\title{
SUPPLEMENT
}

\section{Tight control in the treatment of rheumatoid arthritis: efficacy and feasibility}

\author{
M F Bakker, J W G Jacobs, S M M Verstappen, J W J Bïlsma
}

See end of article for authors' affiliations

Correspondence to M F Bakker, University Medical Center Utrecht, Department of

Rheumatology \& Clinical Immunology, F02.127, PO Box 85500, 3508 GA Utrecht, The Netherlands; m.f.bakker-4@umcutrecht.nl

Accepted 29 June 2007

\begin{abstract}
Objective: To evaluate the available evidence on the efficacy and feasibility of the new concept of tight control in randomised trials in patients with rheumatoid arthritis (RA). Tight control is a treatment strategy tailored to the individual patient with RA, which aims to achieve a predefined level of low disease activity or remission within a certain period of time.

Methods: The literature database PubMed was searched and yielded four trials: the FIN-RACo trial, the TICORA study, the BeSt study and the CAMERA study.

Results: Tight control resulted in greater improvement and a higher percentage of patients meeting the preset aim of low disease activity or remission when compared to the control intervention. In the FIN-RACo trial, aimed at DAS28 $<2.6,51 \%$ of patients in the tight control group achieved remission versus $16 \%$ in the contrast group ( $<<0.001$ ). In the TICORA study, $65 \%$ of patients in the tight control group versus $16 \%$ of the contrast group achieved remission, based on DAS $<1.6$ ( $p<0.0001$ ). In the CAMERA study, $50 \%$ of patients in the tight control group using a computer decision model achieved remission, versus $37 \%$ in the contrast group $(p=0.029)$. The BeSt study consisted of only tight control groups aimed at a DAS $<1.6$; remission was achieved in $38-46 \%$ of patients. This is higher than the range of remission in earlier trials of $13-36 \%$.

Conclusion: Tight control aiming for low disease activity or even better still, remission, seems a promising option in treating patients with RA in clinical trials and probably also in daily practice.
\end{abstract}

$\mathrm{R}$ heumatoid arthritis (RA) is a chronic inflammatory disease that causes joint pain, progressive joint destruction and functional disability, ${ }^{1}$ due to the combined effect of chronic synovitis and progressive joint damage. ${ }^{2}$ Treatment of disease in the first months of synovitis is important to retard radiographic progression. ${ }^{3}$ This window of opportunity suggests that disease activity in patients with early RA is less severe, is characterised by a smaller load of inflammatory cells, and is more responsive to treatment. So aggressive treatment during this phase is more likely to succeed than is the same treatment applied later in the course of disease, ${ }^{4}$ when autoantigens from damaged joints possibly fuel the disease. Therefore it is important that RA should be treated and controlled as soon as possible after diagnosis and that this control should be maintained for as long as possible, consistent with patient safety. ${ }^{5}$

In the past, the traditional (pyramid model) treatment therapy started with non-steroidal anti-inflammatory drugs (NSAIDs). If this treatment was insufficiently effective, secondline antirheumatic drugs or disease-modifying antirheumatic drugs (DMARDs) were added. However, an immediate start of DMARDs proved to be more efficacious than a delayed introduction of DMARDs in the disease progress of RA. ${ }^{78}$ More recent therapeutic strategies are based on combinations of DMARDs to control inflammation in the critical early stages of RA.9-11 Glucocorticoids, which also can be considered as DMARDs because they are able to reduce the progression of joint damage, have been included in DMARD combination treatments of RA. ${ }^{12} 13$

The most current treatment strategies are combination therapies with conventional DMARDs and biologicals. ${ }^{14}$ With these therapies, improvement in signs and symptoms and also low disease activity and even remission come within reach. Overall, a paradigm shift is observed in the trials of RA: treatment is more frequently aimed at low disease activity or remission in each individual patient, ${ }^{15}{ }^{16}$ instead of randomising groups into standardised therapies. This new way of treatment is called "tight control". Tight control may be defined as a treatment strategy tailored to the disease activity of individual patients with RA with the aim of achieving a predefined level of low disease activity or preferably remission within a reasonable period of time.

The aim of this evaluation is to investigate how effective and feasible tight control is.

\section{METHODS}

A PubMed search was performed to look for studies which used a predefined level of disease activity or remission as treatment aim using the following terms: rheumatoid arthritis, randomised trial, treatment strategy, low disease activity, remission and tight control. Abstracts were screened for the tight control principle. The search yielded four studies, in chronological order, the FIN-RACo trial, ${ }^{17}{ }^{18}$ the TICORA study, ${ }^{19}$ the BeSt study, ${ }^{20-22}$ and the CAMERA study. ${ }^{23}$ Different outcome parameters and study designs prohibited pooling of the effects of these studies. Therefore, study characteristics including the aim of the study (low disease activity or remission), time schedule, the method of evaluation of the individual patient, the adaptation of medication, and the results of the studies will be described.

\section{RESULTS}

Table 1 gives an overview of the inclusion criteria and the different treatments used in the four studies. Except for the TICORA study, disease duration was less than 2 years, and the patients had to fulfil the American College of Rheumatology

\footnotetext{
Abbreviations: ACR, American College of Rheumatology; CRP, C-reactive protein; DMARDs, disease-modifying antirheumatic drugs; ESR, erythrocyłe sedimentation rate; NSAIDs, non-steroidal anti-inflammatory drugs; RA, rheumatoid arthritis; SJC, swollen joint score; TJC, tender joint score; VAS, Visual Analogue Scale
} 
Table 1 Characteristics of the tight control studies

\begin{tabular}{llrlll}
\hline Study & $\begin{array}{l}\text { Interventions/groups } \\
\text { FIN-RACo }\end{array}$ & $\mathbf{n}$ & $\begin{array}{l}\text { Medication } \\
\text { at the start }\end{array}$ & Frequency of assessment Inclusion criteria
\end{tabular}

*Based on tight control treatment.

ACR criteria RA, American College of Rheumatism criteria for rheumatoid arthritis; ARA criteria RA, American Rheumatism Association criteria for rheumatoid arthritis; BeSt, Behandel Strategieën; CAMERA, Computer Assisted Management of Early Rheumatoid Arthritis; CRP, C-reactive protein; DAS, disease activity score; DMARD, disease-modifying antirheumatic drug; ESR, erythrocyte sedimentation rate; FIN-RACo, Finnish Rheumatoid Arthritis Combination Therapy; $H C Q$, hydroxychloroquine; h.d., high-dose; i.a., intra-articular; ms, morning stiffness; MTX, methotrexate; predn, prednisone; SJ, swollen joints; SSZ, sulfasalazine; TICORA, Tight Control of Rheumatoid Arthritis; TJ, tender joints; VAS, visual analogue scale; yr, year(s).

(ACR) classification criteria for RA for inclusion. Except for the CAMERA study, the inclusion criteria contained active disease and an age over 18 years.

\section{FIN-RACo}

The Finnish Rheumatoid Arthritis Combination Therapy (FINRACo) study ${ }^{18}$ is a multicentre, randomised open-parallel group treatment trial in which 195 patients were included in the period between 1993 and 1995. The goal of the study was to compare the effects of the combination therapy with DMARDs with those of mono DMARD therapy in patients with early RA. Based on the evaluation of the individual patient, medication was intensified after 3 months in the combination group if there was less than $50 \%$ improvement on two out of three variables: swollen joint score (SJC), tender joint score (TJC), and erythrocyte sedimentation rate (ESR) or C-reactive protein (CRP). In the mono DMARD group medication was intensified if there was less than $25 \%$ improvement after 6 months. The aim of the FIN-RACo study was remission, defined both with the ACR remission criteria, ${ }^{24}$ and as a Disease Activity Score including the 28-joint count $(\mathrm{DAS} 28)^{25}<2.6$, and good treatment response according to criteria of the European League Against Rheumatism (EULAR). ${ }^{26}$ After 2 years, more patients in the combination group had met the ACR remission criteria ( $14 \%$ vs $3 \%, p=0.013)$, the DAS28 remission criterion ( $51 \%$ vs $16 \%, p<0.001$ ), and the criteria of a good treatment response $(67 \%$ vs $27 \%, \mathrm{p}<0.001)$ compared to the mono DMARD group. Combination therapy thus was better and not more hazardous than single treatment in induction of remission in early RA. Combination therapy as a tight control strategy in patients with early RA aiming for remission seems to be more efficacious than monotherapy. ${ }^{17}$

\section{TICORA}

The Tight Control of Rheumatoid Arthritis (TICORA) study ${ }^{19}$ is a single-blind randomised controlled trial in which 111 patients, some with disease duration of up to 5 years, were included between 1999 and 2001. The goal of the study was to compare tight controlled treatment and routine treatment. The evaluation and strategy of medication adaptations and escalations was based on an objective disease activity score in the individual treated, tight control group and evaluated in the routine group by the subjective opinion of the clinician. The outcome of the TICORA study was the mean fall in disease activity score, the number of patients with good response (defined as a DAS28 $<2.4$ after 2 years and a fall in this score from baseline of more than 1.2), and the percentage of patients in remission. The results of TICORA showed that the mean fall in the disease activity score was higher in the tight control group than in the routine group $(-3.5 \mathrm{vs}-1.9$, $\mathrm{p}<0.0001)$. Compared with routine care, patients in the tight control group had a good response ( $82 \%$ vs $44 \%$, p $<0.0001$ ) or remission (DAS28<1.6) (65\% vs $16 \%, \mathrm{p}<0.0001)$. As well as disease activity, radiographic disease progression, physical function and quality of life in the tight control group were also more favourable than in the routine care group, at no additional financial costs.

\section{BeSt}

The Behandel Strategieën (BeSt) study ${ }^{21}$ is a multicentre randomised open clinical trial in which 508 patients with early active RA were included between 2000 and 2002. The goal of the study was to compare four treatment strategies: sequential mono therapy, step-up combination therapy, and initial combination therapy with either high-dose prednisone or infliximab. Evaluation of individual patients was based on Disease Activity Score 44-joint counts (DAS44) in all four groups. ${ }^{27}$ Medication was intensified if DAS44 exceeded 2.4 and was decreased if DAS $\leqslant 2.4$ for the period of 6 months. The outcomes of the BeSt study were functional ability, radiographic joint damage, and the percentages of patients meeting the criterion of low disease activity (DAS44 $\leqslant 2.4$ ) or remission (DAS44<1.6). After 1 year patients of the initial combination therapy including either prednisone or infliximab had earlier functional improvement and less radiographic damage than those on sequential monotherapy or step-up therapy. After 2 years of treatment, these differences seem to disappear and no statistically significant differences were seen between the groups in the percentage of patients in remission $(46 \%, 38 \%$, $41 \%, 42 \%$, respectively; $p=0.7)$. It seems that in patients with early active RA, remarkable clinical improvement and suppression 
of joint damage progression can be achieved with frequent, objective treatment adjustments. ${ }^{20} 22$

\section{CAMERA}

The Computer Assisted Management for Early Rheumatoid Arthritis (CAMERA) study ${ }^{23}$ is a randomised prospective multicentre trial in which 299 patients with early RA were allocated between 1999 and 2003. The goal of the study was to compare intensive with conventional treatment, both strategies aiming for remission. This is the only tight control study comparing the same treatment in a tight control scheme and a conventional scheme. In the intensive (tight control) group, decisions on therapy were made more frequently and with the use of an objective computer decision program evaluation in the individual patient. The computer decision model was based on the SJC, TJC, ESR, and the Visual Analogue Scale (VAS) general well-being. Medication was intensified if less than $20 \%$ improvement had occurred after each month of assessment, unless remission was reached. Every 3 months in the conventional treatment group a decision on medication was made by the clinician, mirroring common practice, and the medication was also intensified when clinically indicated, as judged by the attending physician. Remission was defined as no swollen joints and two out of three of the following variables: number of tender joints $\leqslant 3$, ESR $\leqslant 20 \mathrm{~mm} / \mathrm{hr}^{1 \text { st }}$, and VAS general wellbeing $\leqslant 20 \mathrm{~mm}$. After 2 years, $50 \%$ of the patients in the intensive treatment group versus $37 \%$ in the conventional group $(p=0.029)$ had been in remission for at least 6 months during the study. These results show that tailoring of treatment to the individual patient by a computerised decision program, aiming for remission, is more beneficial than the strategy mirroring daily practice also aiming for remission. Therefore, this strategy could be a helpful tool in daily clinical practice.

\section{DISCUSSION}

In the present report efficacy and feasibility of tight control in randomised trials in patients with early RA is evaluated. It seems that tight control and the aims of low disease activity and remission are feasible and favourable.

Of the four studies, TICORA and CAMERA give the best insight into tight control, since they compared a tight control group with a routine or conventional group. Of these two studies, the CAMERA might offer the best comparison, because in this study the same medication in the same dosage has been used in the tight control group and the conventional groups. In contrast, all intervention groups in the BeSt study make use of the concept of tight control so there is no comparison group. In the FIN-RACo study, the efficacy of a less intensive level of tight control was compared with that of a more intensive level; the latter yielded the best results.

In the evaluated studies different protocols in the tight control groups were used to make therapy choices and changes. In both the TICORA study and the BeSt study therapy changes were based on the DAS score. In the FIN-RACo study as well as the CAMERA study therapy changes were based on the percentage improvement in disease activity of the individual patient. In contrast to FIN-RACo, dose adjustments in the CAMERA study were based on a predefined scheme and were made using a computer decision program which increases objectivity. In the future, the protocol for therapy changes in studies used for tight control should be standardised, enabling comparison and pooling different study outcomes.

The aim in all four studies was the number of patients in remission. The range of remission rates in the tight control groups was significantly better than in the comparison groups (51-65\% remission vs $16-39 \%$ ) or, to make a comparison with historical controls for the groups in the BeSt study (38-46\% remission), the percentages of remission in earlier trials were within a range of $13-36 \% .{ }^{16}{ }^{28}{ }^{29}$ However, different definitions were used to define remission and tight control as a new paradigm needs the use of uniform criteria of low disease activity or remission. Sustained remission is currently, with the arrival of the combination DMARD therapy and the biologicals, an achievable goal in clinical practice. ${ }^{30} 31$ Before the main goal of treatment was to achieve remission, the ACR20/50/70 improvement criteria were standard for controlled clinical trials. But they do not give any information about the current status of disease activity. A patient could have large improvement and still have active disease. ${ }^{32}$ Criteria of low disease activity have the drawback that patients may still have progression of radiographic joint damage. ${ }^{33}$ Therefore remission rather than low disease activity should be our treatment goal today. ${ }^{34}$ On the other hand, even when remission should be the best feasible outcome measure, this term is still poorly defined and various remission criteria mirror different degrees of disease activity. ${ }^{31}{ }^{35}$ In three out of four evaluated studies, the $\mathrm{DAS}^{27}$ remission criteria were used to define remission. However, the DAS has not been validated for use in individual patients. It is rather sensitive for changes in ESR in the (nearly) normal range (see fig 1). ${ }^{36}$ Figure 1 shows that the relative contribution of tender joints to the DAS28 score is much higher than that of swollen joints, which is a more specific feature of RA. The DAS could lead to overestimation of disease activity in individual patients due to the DAS components TJS and VAS general well-being. Another problem for assessment of individual patients with RA is that the DAS28 does not include joints of the feet, which are frequently inflamed in RA. This could lead to underestimation of disease activity. The DAS28 remission criterion at a cut-off level of 2.6 has been found to lack construct validity for use in clinical practice for this reason. ${ }^{37}$

In our opinion, for the practical use of tight control, a new score should be developed and validated for the assessment in individuals, enabling comparison and pooling of different study strategies. Probably the key criterion should be absence of swollen joints, because this is the key feature for RA. Further points of discussion are the duration of remission and whether or not radiographic progression should be included in remission criteria.

Overall, frequent monitoring on the basis of objective evidence of continued disease activity using a validated outcome measure and a quick, aggressive escalation protocol can improve the effects of RA considerably compared with routine care. ${ }^{78}{ }^{39}$ Other short-term and long-term advantages of tight control might be the greater improvement in physical function and substantially enhanced quality of life, ${ }^{19}$ improved functional capacity, ${ }^{31}$ decline of radiographic progression, ${ }^{20} 22$ and possible cost reductions for the future. ${ }^{19}$ The disadvantages of tight control might be the frequency and intensity of the assessments, although the frequency might be high in patients with early RA but lower in established disease, and the fear of patients of overtreatment due to the aggressive escalation protocol. The solution for overtreatment might be reduction of medication in case of sustained response as applied in the BeSt and CAMERA study.

\section{CONCLUSION}

Tight control seems to be a promising new paradigm for reaching the aim of low disease activity, or even better remission, in clinical trials and possibly daily practice, due to a predefined decision and measurement system. For further implementation of this concept, development of a valid and easy-to-use criterion for remission is recommended. 

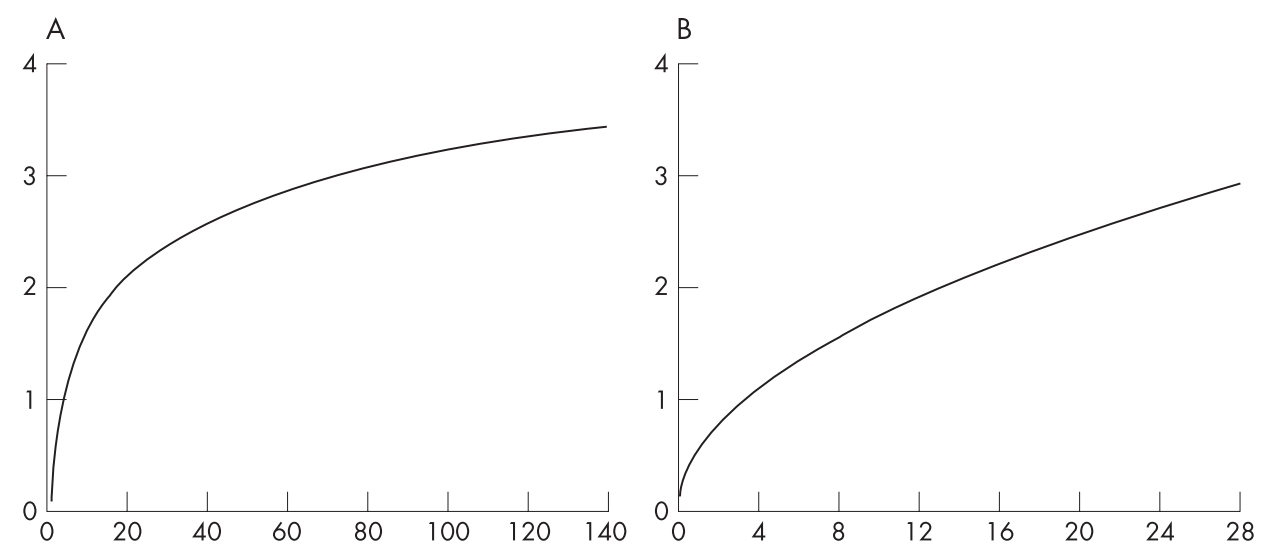

Figure 1 Plots of contribution of individual components of the DAS28 (x-axis) to the total DAS28 score (y-axis). (A) ESR $\left(0.7^{*} \operatorname{LN}(x)\right)$. (B) Tender joint count $\left(0.555^{*} \mathrm{SQR}(\mathrm{x})\right)$. (C) Swollen joint count $\left(0.284^{*} S Q R(x)\right)$. (D) Visual analogue scale patient's global assessment $\left(0.0142^{*}(x)\right)$. ESR, erythrocyte sedimentation rate; VAS, visual analogue scale.
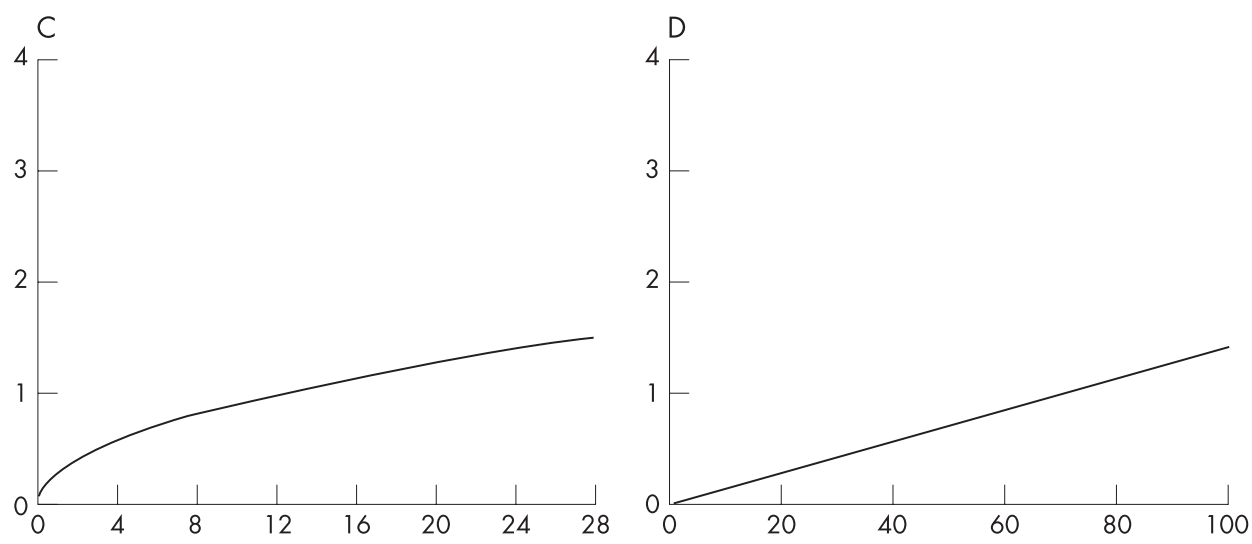

\section{Authors' affiliations}

M F Bakker, J W G Jacobs, S M M Verstappen, J W J Biilsma, Department of Rheumatology and Clinical Immunology, University Medical Center Utrecht, Utrecht, The Netherlands

Competing interests: None declared.

\section{REFERENCES}

1 Scott DL, Symmons DP, Coulton BL, Popert AJ. Long-term outcome of treating rheumatoid arthritis: results after 20 years. Lancet 1987;1:1108-11.

2 Pollard L, Choy EH, Scott DL. The consequences of rheumatoid arthritis: quality of life measures in the individual patient. Clin Exp Rheumatol 2005;23:S43-52.

3 Raza K, Buckley CE, Salmon M, Buckley CD. Treating very early rheumatoid arthritis. Best Pract Res Clin Rheumatol 2006;20:849-63.

4 Boers M. Understanding the window of opportunity concept in early rheumatoid arthritis. Arthritis Rheum 2003:48:1771-4.

5 Moreland LW, Russell AS, Paulus HE. Management of rheumatoid arthritis: the historical context. J Rheumatol 2001;28:1431-52.

6 Wolfe F, Cush JJ, O'Dell JR, Kavanaugh A, Kremer JM, Lane NE, et al. Consensus recommendations for the assessment and treatment of rheumatoid arthritis. J Rheumatol 2001;28:1423-30.

7 Smolen JS, Aletaha D, Machold KP. Therapeutic strategies in early rheumatoid arthritis. Best Pract Res Clin Rheumatol 2005;19:163-77.

8 van der Heide A, Jacobs JW, Bijlsma JW, Heurkens AH, van Booma-Frankfort C, Van der Veen MJ, et al. The effectiveness of early treatment with "second-line" antirheumatic drugs. A randomized, controlled trial. Ann Intern Med 1996; 124:699-707.

9 Capell HA, Madhok R, Porter DR, Munro RA, Mclnnes IB, Hunter JA, et al. Combination therapy with sulfasalazine and methotrexate is more effective than either drug alone in patients with rheumatoid arthritis with a suboptimal response to sulfasalazine: results from the double-blind placebo-controlled MASCOT study. Ann Rheum Dis 2007;66:235-41.

10 Landewe RB, Boers M, Verhoeven AC, Westhovens R, van de Laar MA Markusse $\mathrm{HM}$, et al. COBRA combination therapy in patients with early rheumatoid arthritis: long-term structural benefits of a brief intervention. Arthritis Rheum 2002:46:347-56.

11 Wilske KR, Healey LA. Remodeling the pyramid: a concept whose time has come. J Rheumatol 1989;16:565-7.

12 Bïlsma JW, Hoes JN, Van Everdingen AA, Verstappen SM, Jacobs JW. Are glucocorticoids DMARDs? Ann N Y Acad Sci 2006;1069:268-74.

13 Kirwan JR, Bijlsma JW, Boers M, Shea BJ. Effects of glucocorticoids on radiological progression in rheumatoid arthritis. Cochrane Database Syst Rev 2007;CD006356.
14 van der Heijde D, Klareskog L, Rodriguez-Valverde V, Codreanu C, Bolosiu H Melo-Gomes J, et al. Comparison of etanercept and methotrexate, alone and combined, in the treatment of rheumatoid arthritis: two-year clinical and radiographic results from the TEMPO study, a double-blind, randomized trial. Arthritis Rheum 2006;54:1063-74.

15 Fransen J, Moens HB, Speyer I, van Riel PL. Effectiveness of systematic monitoring of rheumatoid arthritis disease activity in daily practice: a multicentre, cluster randomised controlled trial. Ann Rheum Dis 2005;64:1294-8.

16 Svensson B, Schaufelberger C, Teleman A, Theander J. Remission and response to early treatment of RA assessed by the Disease Activity Score. BARFOT study group. Better Anti-rheumatic Farmacotherapy. Rheumatology (Oxford) 2000;39:1031-6.

17 Makinen H, Kautiainen H, Hannonen P, Mottonen T, Leirisalo-Repo M, Laasonen $\mathrm{L}$, et al. Sustained remission and reduced radiographic progression with combination disease modifying antirheumatic drugs in early rheumatoid arthritis. J Rheumatol 2007;34:316-21.

18 Mottonen T, Hannonen P, Leirisalo-Repo M, Nissila M, Kautiainen $H$, Korpela $M$, et al. Comparison of combination therapy with single-drug therapy in early rheumatoid arthritis: a randomised trial. FIN-RACo trial group. Lancet 1999;353:1568-73.

19 Grigor C, Capell H, Stirling A, McMahon AD, Lock P, Vallance R, et al. Effect of a treatment strategy of tight control for rheumatoid arthritis (the TICORA study): a single-blind randomised controlled trial. Lancet 2004;364:263-9.

20 Allaart CF, Goekoop-Ruiterman YP, de Vries-Bouwstra JK, Breedveld FC, Dijkmans BA, Group FS. Aiming at low disease activity in rheumatoid arthritis with initial combination therapy or initial monotherapy strategies: the BeSt study. Clin Exp Rheumatol 2006;24:S077-82.

21 Goekoop-Ruiterman YP, de Vries-Bouwstra JK, Allaart CF, van Zeben D, Kerstens PJ, Hazes JM, et al. Clinical and radiographic outcomes of four different treatment strategies in patients with early rheumatoid arthritis (the BeSt study): a randomized, controlled trial. Arthritis Rheum 2005;52:3381-90.

22 Goekoop-Ruiterman YP, de Vries-Bouwstra JK, Allaart CF, van Zeben D, Kerstens PJ, Hazes JM, et al. Comparison of treatment strategies in early rheumatoid arthritis: a randomized trial. Ann Intern Med 2007;146:406-15.

23 Verstappen SM, Jacobs JW, Van D, V, Heurkens AH, Schenk Y, Ter Borg EJ, et al. Intensive treatment with methotrexate in early rheumatoid arthritis: aiming for remission. Computer Assisted Management in Early Rheumatoid Arthritis (CAMERA). Ann Rheum Dis, 2007. Accepted for publication.

24 Arnett FC, Edworthy SM, Bloch DA, McShane DJ, Fries JF, Cooper NS, et al. The American Rheumatism Association 1987 revised criteria for the classification of rheumatoid arthritis. Arthritis Rheum 1988;31:315-24.

25 Prevoo ML, van't Hof MA, Kuper HH, van Leeuwen MA, van de Putte $L B$, van Riel PL. Modified disease activity scores that include twenty-eight-joint counts. Development and validation in a prospective longitudinal study of patients with rheumatoid arthritis. Arthritis Rheum 1995;38:44-8. 
26 van Gestel AM, Prevoo ML, van't Hof MA, van Rijswijk MH, van de Putte $L B$, van Riel PL. Development and validation of the European League Against Rheumatism response criteria for rheumatoid arthritis. Comparison with the preliminary American College of Rheumatology and the World Health Organization/ International League Against Rheumatism Criteria. Arthritis Rheum 1996;39:34-40.

27 van der Heijde DM, van't Hof M, van Riel PL, van de Putte LB. Development of a disease activity score based on judgment in clinical practice by rheumatologists. $J$ Rheumatol 1993;20:579-81.

28 Mottonen T, Paimela L, Leirisalo-Repo M, Kautiainen $H$, llonen J, Hannonen P. Only high disease activity and positive rheumatoid factor indicate poor prognosis in patients with early rheumatoid arthritis treated with "sawtooth" strategy. Ann Rheum Dis 1998:57:533-9.

29 Teir J, Gray J, Pendlebury A, Grennan DM. Outcome of patients with early rheumatoid arthritis over a two year period. Ann Rheum Dis 1999:58:323.

30 Combe B, Landewe R, Lukas C, Bolosiu HD, Breedveld F, Dougados M, et al. EULAR recommendations for the management of early arthritis: report of a task force of the European Standing Committee for International Clinical Studies Including Therapeutics (ESCISIT). Ann Rheum Dis 2007;66:34-45.

31 Mierau M, Schoels M, Gonda G, Fuchs J, Aletaha D, Smolen JS. Assessing remission in clinical practice. Rheumatology (Oxford) 2007;46:975-9.
32 Ranganath VK, Khanna D, Paulus HE. ACR remission criteria and response criteria. Clin Exp Rheumatol 2006;24:S014-21.

33 Molenaar ET, Voskuyl AE, Dinant HJ, Bezemer PD, Boers M, Dijkmans BA Progression of radiologic damage in patients with rheumatoid arthritis in clinical remission. Arthritis Rheum 2004;50:36-42.

34 Smolen JS, Aletaha D. What should be our treatment goal in rheumatoid arthritis today? Clin Exp Rheumatol 2006;24:S007-13.

35 Makinen H, Hannonen P, Sokka T. Definitions of remission for rheumatoid arthritis and review of selected clinical cohorts and randomised clinical trials for the rate of remission. Clin Exp Rheumatol 2006;24:S022-8.

36 van der Heijde DM, Jacobs JW. The original "DAS" and the "DAS28" are not interchangeable: comment on the articles by Prevoo et al. Arthritis Rheum 1998;41:942-5.

37 Landewe $\mathbf{R}$, van der Heijde D, van der Linden S, Boers M. Twenty-eight-joint counts invalidate the DAS28 remission definition owing to the omission of the lower extremity joints: a comparison with the original DAS remission. Ann Rheum Dis 2006;65:637-41

38 Emery P. Treatment of rheumatoid arthritis. BMJ 2006;332:152-5.

39 Zeidler H, Hulsemann JL. How should best strategy and tight control be translated into clinical practice? Comment on the article by Goekoop-Ruiterman et al. Arthritis Rheum 2006;54:2338-9. 
3. Gran JT, Husby G. Ankylosing spondylitis: prevalence and demography. In: Klippel JH, Dieppe P, editors.Rheumatology, 2nd edition. London: Mosby International, 1998:15.1-6.

4. Muller I, Bockarie M, Alpers M, Smith T. The epidemiology of malaria in Papua New Guinea. Trends Parasitol 2003;19:253-9.

5. Shankarkumar U, Devaraj JP, Ghosh K, Karnad D, Anand K, Mohanty D. HLA associations in $\mathrm{P}$ falciparum malaria patients from Mumbai, western India. Indian J Malariol 2002;39:76-82.

6. Dean M, Carrington M, O'Brien SJ. Balanced polymorphism selected by genetic versus infectious human diseases. Annu Rev Genomics Hum Genet 2002;3:263-92.

7. Gao X, Nelson GW, Karacki P, Martin MP, Phair J, Kaslow R, et al. Effect of a single amino acid change in MHC class I molecules on the rate of progression to AIDS. N Engl J Med 2001;344:1668-75

8. Blanco-Gelaz MA, Lopez-Vazquez A, Garcia-Fernandez S, Martinez-Borra J, Gonzalez S, Lopez-Larrea C. Genetic variability, molecular evolution, and geographic diversity of HLA-B27. Hum Immunol 2001;62:1042-50.

9. Fiorillo MT, Cauli A, Carcassi C, Bitti PP, Vacca A, Passiu G, et al. Two distinctive HLA haplotypes harbor the B27 alleles negatively or positively associated with ankylosing spondylitis in Sardinia: implications for disease pathogenesis. Arthritis Rheum 2003;48:1385-9.

10. McGuire W, Hill AV, Allsopp CE, Greenwood BM, Kwiatkowski D. Variation in the TNF-alpha promoter region associated with susceptibility to cerebral malaria. Nature 1994;371:508-11.

\section{Correction}

There was an error in an article published in supplement III last year (Bakker MF, Jacobs JWG, Verstappen SMM, Bijlsma JWJ. Tight control in the treatment of rheumatoid arthritis: efficacy and feasibility. Ann Rheum Dis 2007;66:iii56-iii60). The reported remission rates of the FIN-RACo trial were of the subset of patients who completed the study and were in sustained remission, which hampers comparison between the studies because the 2 year point remission rates on intention to treat basis were reported for the other three studies. The 2 year intention to treat point remission rates of the FIN-RACo study for ACR remission are 37\% in the tight control group and $18 \%$ in the contrast group. For DAS-remission (DAS28<2.6), completers' remission rates of the FIN-RACo trial are $68 \%$ and $41 \%$, respectively. The amendments to the article are as follows:

Abstract, piii56, line 8 from top should read "In the FIN-RACo trial, analysing the subset of patients completing the study, $68 \%$ in the tight control group achieved remission (DAS28<2.6) versus $41 \%$ in the contrast group."

Text, piii57, column 1, line 17 from bottom should read "After 2 years, more patients in the combination group compared with the mono DMARD group had met the ACR remission criteria ( $37 \%$ vs $18 \%, p=0.003$ )". Analysing the subset of patients completing the study, $68 \%$ vs $41 \%$ met the DAS28 remission criterion $(p<0.001)$ and $67 \%$ vs $27 \%(p<0.001)$ the criteria of sustained good treatment response, respectively."

So these reported 2 year remission rates of the FIN-RACo trial are more favourable than those reported erroneously in the paper. The authors believe that this further strengthens their conclusion that tight control aiming for low disease activity and remission is a promising option in treating patients with early RA in daily clinical practice. 